International Journal on Intelligent Electronic Systems, Vol. 5, No.1, January 2011

\title{
IMPLEMENTATION OF PERFORMANCE ANALYSIS OF 18-PULSE AC-DC CONVERTER FED SWITCHED RELUCTANCE MOTOR DRIVES TO ROBOTICS
}

\author{
Rama Subbamma M. ${ }^{1}$, Balaji Chakravarthy P. ${ }^{2}$, Dwarakanath M.L., ${ }^{3}$ Madhusudhan V. \\ 1,2,3 Department of Electrical Engineering, SSITS, Rayachoty, A.P, India. \\ ${ }^{4}$ Department of Electrical Engineering, MEC, Secundrabad, A.P, India
}

\begin{abstract}
In this paper, design of autotransformer based 18 Step AC-DC converter fed vector controlled Switched Reluctance motor drive is presented and its Matlab/Simulink model is given. The design procedure for proposed autotransformers shows the flexibility in the design for making it a cost effective replacement suitable for retrofit applications, where presently a six pulse diode bridge rectifier is used. Using 18-pulse configuration of the vector controlled Switched Reluctance motor drive (VCSMD) the higher order harmonics (even 13) is being suppressed. Simulation results of SRMD were obtained in MATLAB \& SIMULINK with NO LOAD \& ON LOAD.
\end{abstract}

Keywords: Autotransformer, multi pulse AC-DC converter, power quality, and vector controlled Switched reluctance motor drive (VCSRMD).

\section{INTRODUCTION}

With the evolution of power-electronic converters, the majority of dc drives are being replaced by permanent magnet switched reluctance motor drives. These drives are generally operated in vector control, as it is an best way of achieving high- performance control of motors in a way similar to the dc motor. These vector-controlled switched reluctance motor drives (SRMDs) are fed by an controlled ac-dc converter which results in injection of current harmonics into the supply system. These current harmonics, while propagating through the finite source impedance, result in voltage distortion at the point of common coupling, there by affecting the nearby consumers.

Various methods based on the principle of increasing the number of pulses in ac-dc converters have been reported in the literature to mitigate current harmonics [2]-[4]. These methods use two or more converters, where the harmonics generated by one converter are cancelled by another converter, by proper phase shift. The autotransformer-based configurations $[5,6]$ provide the reduction in magnetics rating, as the transformer magnetic coupling transfers only a small portion of the total kilovolt-ampere of the permanent magnet synchronous motor drive. These autotransformer based schemes considerably reduce the size and weight of the transformer. Autotransformer-based 18-pulse ac-dc converters have been reported for reducing the total harmonic distortion (THD) of the ac mains current. To ensure equal power sharing between the diode bridges and to achieve good harmonic cancellation, this topology needs Inter phase transformers and impedance matching inductors, resulting in increased complexity and cost. Moreover the dc-link voltage is higher, making the scheme non applicable forretrofit applications.

To overcome the problem of higher dc-link voltage, Hammond [5] has proposed a new topology, but the transformer design is very complex. To simplify the transformer design, Paice [6] has reported a new topology for 18- pulse ac-dc Converters But this topology requires higher rating magnetics, resulting in the enhancement of capital cost. Bhim Singh $[9,11]$ also gives various VCSRMD model with various autotransformer connections.

In this paper, an 18-pulse Ac-Dc converter fed vector controlled switched reluctance motor drive (VCSRMD) is simulated, which is used an novel autotransformer for 18- pulse production. The presented techniques for the design of the autotransformer provides flexibility in design to vary the output voltages to make it suitable for retrofit applications (where presently, a six-pulse converter is being used) without much alterations in the system layout. This topology results in improvement in THD of ac mains current and power factor even under light load conditions.

\section{DESIGN OF AUTOTRANSFORMERS FOR 18-PULSE AC-DC CONVERTER}

The minimum phase shift required for proper harmonic elimination is given by [2]- Phase Shift $=600$ /No. of 6 -pulse Converters To achieve the 18-pulse 
rectification, the following conditions have to be atisfieda). Three sets of balanced three-phase line voltages are to be produced, which are \pm 200 or 400 for 18-pulse required out of phase with respect to each other. Here, $/ \pm 200$ phase shift is used to reduce the size of the magnetic. (b) The magnitude of these line voltages should be equal to each other to result in symmetrical pulses and reduced ripple in output dc voltage.Fig.2 shows the winding connection diagram of the proposed autotransformer for achieving 18-pulse rectification. The phasor diagram shown in Fig. 3 represents the relationship among various phase voltages.

Assume the following set of voltages:

$V=V L 0^{\circ} V=V L-120^{\circ} \mathrm{V}=V L 120^{\circ} a b c$

$V^{\prime}=V L+20^{\circ} V^{\prime}=V L-100^{\circ} V=V L 140^{\circ} a b c(2)$

Here $V_{a}, V_{b}$, and $V_{c}$ are the phase voltages.

Similarly-

$V^{\prime \prime}=V L-20, V^{\prime}=V L-140^{\circ} V^{\prime}=V L 100^{\circ} a b c$

Where, $V$ is the rms value of phase voltage.



Fig. 1 Winding connection diagram of the proposed autotransformer for 18-Pulse

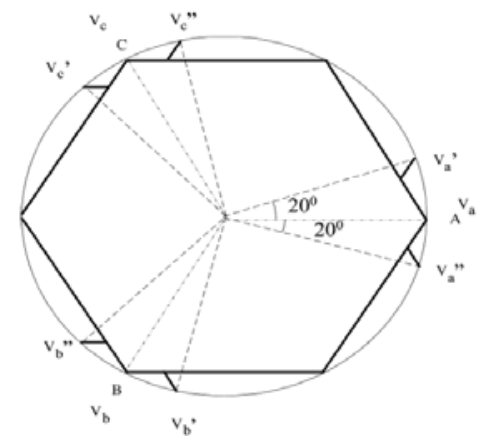

Fig. 2 Vector diagram of Phase Voltages for 18-

Pulse ac-dc converter
The phase shifted voltages for phase "a" of are

$$
\begin{aligned}
& V_{a}^{\prime}=V_{a}+0.25777 V_{c}-0.1371 V_{b} \\
& V a^{\prime \prime}=V_{a}+0.25777 V_{b}-0.1371 V_{c}
\end{aligned}
$$

Similarly phase shifted voltages for phase "b" are-

$$
\begin{aligned}
& V_{b}^{\prime}=V_{b}+0.25777 V_{a}-0.1371 V_{c} \\
& V_{b}{ }^{\prime \prime}=V_{b}+0.25777 V_{c}-0.1371 V_{a}
\end{aligned}
$$

Similarly phase shifted voltages for phase "c" are

$$
\begin{aligned}
& V_{c}^{\prime}=V+0.25777 V-0.1371 V \\
& V_{c}^{\prime \prime}=V+0.25777 V-0.1371 V
\end{aligned}
$$

Thus, the autotransformer uses two auxiliary windings per phase. A phase-shifted voltage is obtained. Due to the 18-pulse operation, the average voltage at $d c$ link is higher than that of a six-pulse diode bridge rectifier output voltage by about $3.7 \%$. The proposed autotransformer design has been modified to make it suitable for retrofit applications (to achieve the dc link voltage same as that of six-pulse diode bridge rectifier). For the generalized arrangement of the autotransformer windings for varying the transformer output voltages while still maintaining the 18-pulse operation (ensuring an angle of $20^{\circ}$ between the transformer output voltages with respect to the supply voltages). This can be achieved by simply varying the tapping positions on the winding.

For achieving this, all the three-phase shifted voltages, i.e., and are reduced by about 3.7\% from the supply voltage, for retrofit arrangement in 18- pulse operation respectively as- By following the above procedure, for same dc link voltage as that of six-pulse diode bridge rectifier, the values of $\mathrm{K} 3, \mathrm{~K} 4, \mathrm{~K} 5$ and $\mathrm{K} 6$ are calculated for retrofit arrangement as a

$$
\begin{aligned}
& V_{a 1} \times 0.963 V a=V a+K 5 V_{b}+K 6 V_{c} \\
& V_{a 1}{ }^{\prime}=0.963 V_{a}^{\prime}=V a+K 3 V_{c}+K 4 V_{b} \\
& V_{a 1}{ }^{\prime \prime}=0.963 V_{a} K^{\prime}=V_{a}+K 3 V_{b}-K 4 V_{c}
\end{aligned}
$$

Where $V A 1^{\prime}, V a 1^{\prime \prime}$ \& $V a 1^{\prime \prime}$ are the reduced phase voltages for the retrofit arrangement of the proposed 18-pulse ac-dc converter. By solving above 
equations $\mathrm{K} 3, \mathrm{~K} 4, \mathrm{~K} 5$ and $\mathrm{K} 6$ are calculated. These equations result

in

$K 3=0.2852, K 4=0.09485, K 5=0.0 .0371 \quad$ and

$K 6=0.0371$ for the desired phase shift in autotransformer.

The phase shifted voltages for phase "a" are

$$
\begin{aligned}
& V a 1=V_{a}+0.0371 V_{b}+0.0371 V_{c} \\
& V a 1^{\prime}=V_{a}+0.2852 V_{c}-0.09485 V_{b} \\
& V_{a}^{\prime \prime}=V_{a}+0.2852 V_{b}-0.09485 V_{c}
\end{aligned}
$$

Similarly, phase shifted voltages for phase "b" are

$$
\begin{aligned}
& V_{b 1}=V_{b}+0.0371 V_{a}+0.0371 V_{c} \\
& V_{b 1}{ }^{\prime}=V_{b}+0.2852 V_{a}-0.09485 V_{c} \\
& V_{b}{ }^{\prime \prime}=V_{b}+0.2852 V_{c}-0.09485 V_{a}
\end{aligned}
$$

Similarly, phase shifted voltages for phase "c" arec

$$
\begin{aligned}
& V_{c 1}=V_{c}+0.0371 V_{b}+0.0371 V_{a} \\
& V_{c 1}^{\prime}=V_{c}+0.2852 V_{b}-0.09485 V_{a} \\
& V_{c}^{\prime \prime}=V_{c}+0.2852 V_{a}-0.09485 V_{b}
\end{aligned}
$$

Thus, by simply changing the transformer winding tapping, the same dc link voltage as that of 6-pulse diode bridge rectifier is obtained. The kVA rating of the autotransformer is calculated as $k V A=0.5 \Sigma_{V}$ winding Iwinding (23)

Fig.4 shows the schematic diagram of proposed autotransformer based 18 -pulse ac-dc converter with a phase shift of +200 and -200 along with the pulse multiplication circuit, resulting in 18-pulse ac-dc converter, referred as Topology $C$ and Fig. 5 shows the schematic diagram of proposed autotransformer based 18-pulse ac-dc converter suitable for retrofit applications.

\section{INTRODUCTION TO SRMD}

With the advent of modern control technology and power electronic, switched reluctance motor drive are becoming increasingly popular. Because of high efficiency over wide operating range, the absence of rotor windings, and the maintenance free type of motor, SRMs have some advantages over other types of electrical machines. The work by Prof. Peter Lawrenson of England in 1980 and Speed consortium of the University of Glasgow substantially contributed to advancement of switched reluctance motor.

\subsection{Basic Principle Of SRM:}

The switched reluctance motor is a rotating electric machine where both, stator and rotor have salient poles. The stator consists of simple concentric windings. There are neither windings or bar wires on the rotor. Stator windings on diametrically opposite poles are connected in series form to a single phase. When the stator pole pair is energized by the phase winding, the nearest rotor pole pair is attracted toward the position, where the magnetic path has the minimum reluctance. Thus, by energizing the consecutive stator phases in sequence, it is possible to develop a torque in either direction of rotation.

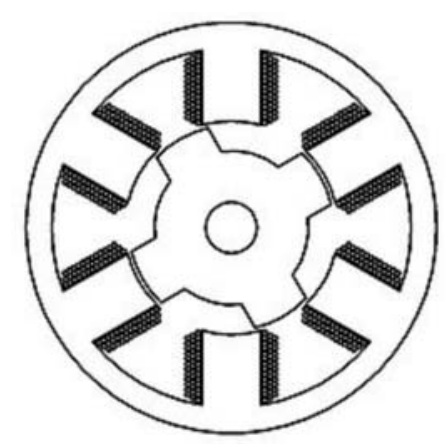

Fig. 3. Cross-section of switched reluctance machine with 6 stator and 4 rotor poles.

\subsection{MODELING OF VCSRMD}

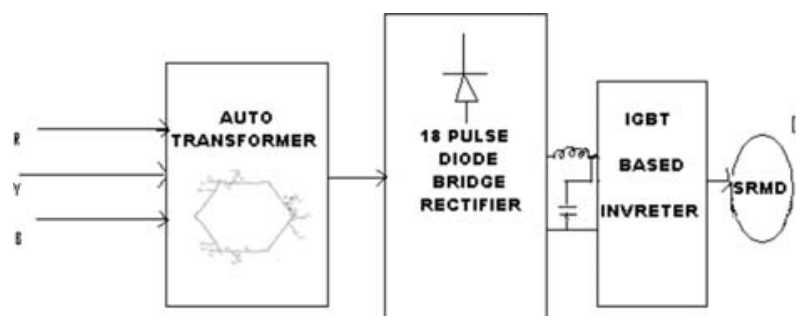

Fig. 4. Modelling of VCSRMD 


\section{SIMULINK DIAGRAM}



Fig. 5. Simulink Diagram

Fig 5 shows the SIMULINK diagram of a 18 pulse AC -DC converter fed SRM and their results as below

\section{SIMULATION RESULTS:}

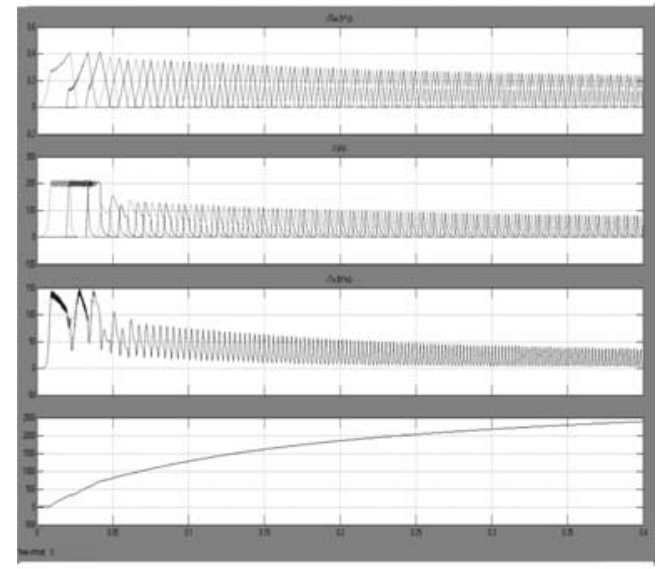

Fig. 6. Output of SRM



Fig. 7. Auto transformer output Rectifier output 




Fig. 8. THD at supply mains



Fig. 9. THD at Load

\section{CONCLUSION}

The design, modeling, simulation, and development of 18-pulse ac-dc converter fed VCSRMD has been presented for various load. It has been observed that the design of the proposed autotransformer is flexible for making it suitable for retrofit applications, where presently a six-pulse diode bridge rectifier is being used. The proposed 18-pulse ac-dc converter fed VCSRMD has less THD.

\section{REFRENCES}

[1] P. Vas, "Sensorless Vector and Direct Torque Control", Oxford, U.K.:Oxford Univ. Press, 1998.

[2] D. A. Paice, "Power Electronic ConverterHarmonics: Multipulse Methods for Clean m, Power", Piscataway, NJ: IEEE Press, 1996.

[3] S. Choi, P. N. Enjeti, and I. J. Pitel, "Polyphase transformer arrangements with reduced kVA capacities for harmonic current reduction in rectifier type utility interface," IEEE Transactions on Power Electronics, Vol. 11, No. 5, Sepimeber 1996 pp. 680-689.

[4] D.A.Paice, "Multipulse converter system," U.S. Patent 4876634, October 24, 1989.

[5] P. W. Hammond, "Autotransformer," U.S. Patent no. 5619407, April 8, 1997.

[6] D. A. Paice, "Transformers for Multipulse AC/DC Converters," U.S.Patent no. 6101113, Auguest 8, 2000.

[7] "IEEE Guide for Application and Specification of Harmonic Filters", IEEE Std. 1573, 2003.

[8] "IEEE Guide for Harmonic Control and Reactive Compensation of Static Power Converters", IEEE Std. 519, 1992.

[9] Rajashekara K., Kawamura A., Matsuse K.: Sensorless Control of AC Motor Drives, ISBN 0-7803-1046-2, New York, IEEE Press, 1996.

[10] Maòa, M.: Pohon se spínanm reluktanèním motorem, Diplomová práce, Brno, 2001

[11] Višinka, R.: On-fly phase resistance estimation of switched reluctance motor for sensorless based control techniques, Ph.D Thesis, Brno, 2002.

[12] A. Uan-Zo-li, F.Wang, D. Boroyevich, F.Lacaux, and A. Tardy, "Comparison of prospective topologies for aircraft autotransformer-rectifier units," Proceeding of IEEE IECON'03, Vol. 2, November 2003, pp. 1121-1127.

[13] F. J. Chivite-Zabalza, A. J. Forsyth, and D. R. Trainer, "Analysis and practical evaluation of an 18-pulse rectifier for aerospace applications," Proceeding of IEEE PEMD'04, 2004, pp. 338-343. 